\title{
A LITERATURE REVIEW: URBAN TEENAGERS' READINESS TO IMPROVE THE QUALITY OF LIFE TOWARD THE MENARCHE
}

\author{
Anita Setyawati ${ }^{1}$, Restuning Widiasih ${ }^{1}$, Ida Maryati $^{1}$, Ermiati $^{1}$, Ardhini Dwi Utari ${ }^{1}$, Rinda Intan Sari ${ }^{1}$ \\ ${ }^{1}$ Faculty of Nursing, Universitas Padjadjaran \\ Corresponding email: anita.setyawati@unpad.ac.id
}

\begin{abstract}
Menarche is the first experience of menstruation would cause anxiety among teenagers, fear, discomfort, and affect the quality of life of teenage. This condition was caused by the taboo assumption to discuss menstruation with family and their environment. Therefore, this study was conducted to identify urban teenagers' readiness toward menarche. This study was conducted with the process of searching, collecting and analyzing articles. The search sources used were Cinahl, Scopus, Cochrane, Pubmed, and Cengage databases. The keywords used were menarche, readiness, and urban teenagers. The inclusion criteria used were 2013 - 2018 research articles, full text, and English articles. The exclusion criteria used was non-urban teenagers. According to the keyword was found 124 articles. After being selected based on the inclusion and exclusion criteria, 7 articles were analyzed. The result showed urban teenagers' readiness consisted of internal and external readiness. Internal readiness consists of age and knowledge. Internal readiness can affect self-acceptance, maturity of mind, and views on the stages of growth and development that are being faced. External readiness consists of social support. Social support for urban teenagers is useful to get information and attention when menarche. External readiness for urban teenagers was already good but lack of internal readiness. Therefore, counseling and health education related to menarche was needed starting from elementary school.
\end{abstract}

Keywords: Menarche, readiness, urban teenager.

\section{INTRODUCTION}

Teenager period is a transition from childhood to adulthood that characterized by puberty. The sign of a teenager with puberty or physical maturity could be shown from the body and hormonal changes. This change generally occurs at the age of 12-16 years and can occur quickly and dramatically. Hormonally there will be an increase sexual hormones such as estrogen which affect the body changes among young girl such as breast growth, the hip enlargement, hair growth on the vagina and armpits, and sexual maturity with the first menstruation was called menarche (Proverawati \& Misaroh, 2009).

Menarche was a personal experience and teenagers tend to feel uncomfortable to talk about it, even for some ethnicities it is still taboo to talk about, including in the family. So, the early adolescents lack readiness when physical changes occur especially in menarche period. In addition, mental readiness was very necessary, because feelings of anxiety and fear will arise if the teenager has to lack understanding about menarche. For this reason, they need to be prepared in the face of the arrival of menarche (Sukarni \& Wahyu, 2013). 
Anita Setyawati : A Literature Review: Urban Teenagers' Readiness to Improve The Quality of Life

Based on the literature, it was known that post-menarche among teenager claim to be unprepared when they in menarche period. They feel worried, strange, and secret when experiencing menarche. Conversely, the young girl who has received information about menstruation before they experience menarche reported that they already know about menarche and know what to do (Marvan \& Alcala-Herrera, 2014).

The impact of teenage girls' unpreparedness for menarche was increases discomfort during menarche, increases the number of absentees at school during menstruation, and the majority of teenage girls will keep secret when experiencing menarche. Even among teenage girls who were identical with activeness in many activities but when it have menarche period, so it can limit their daily activities. In other words, the unpreparedness for menarche affects the quality of life among teenage girl. Therefore, the authors were interested in knowing how to deal with menarche that affects the quality of life among young girls living in the urban area. This study was conducted to identify urban teenagers' readiness toward menarche.

\section{METHODS}

This systematic review process was carried out with the Systematic Review Approach. To get the final result with this approach through several steps, include:

1. Determine the topic of literature. This study focused on information relating to the readiness of young girls facing the menarche.

2. Find and search for literature sources from online databases, such as CINAHL/ Ebsco, Scopus, Cochrane, Pubmed, and Cengage. The keywords used were "menarche", "preparation" and "teenagers in urban area". The results of the article search were found in CINAHL / Ebsco by 32 articles, Scopus by 39 articles, Cochrane by 29 articles, Pubmed by 17 articles, and Congage by 7 articles.

3. Select the most relevant and suitable sources according to the research objectives. The inclusion criteria for articles were studies published in the last 5 years (2013-2018), full text and in English. Finally, these were found 7 articles consisting of 2 articles from CINAHL/ Ebsco databases, Scopus 3 articles, and Pubmed 2 articles.

4. Organizing and analyzing the articles that were selected and comparing with the other countries and the existing theories relating to the readiness of menarche among teenage girls.

5. Summarize in the form of tables and discuss the result part of these studies. 


\section{Diagram 1. The Steps of Systematic Review Approach}

\begin{tabular}{|c|c|}
\hline $\begin{array}{l}\text { CINAHL/EBsco: } 32 \text { articles, } \\
\text { Scopus: } 39 \text { articles, Cochrane: } 29 \\
\text { articles. Pubmed: } 17 \text { articles and }\end{array}$ & $\begin{array}{l}124 \text { articles were obtained based } \\
\text { on kev words and publication vear }\end{array}$ \\
\hline$\downarrow$ & $\begin{array}{l}29 \text { articles were obtained based on } \\
\text { title criteria }\end{array}$ \\
\hline $\begin{array}{l}\text { CINAHL/EBsco: } 10 \text { articles, } \\
\text { Scopus: } 9 \text { articles, Cochrane: } 2 \\
\text { articles. Puhmed: } 7 \text { articles and }\end{array}$ & \\
\hline$\nabla$ & $\begin{array}{l}21 \text { articles were obtained based on } \\
\text { fulltext criteria }\end{array}$ \\
\hline $\begin{array}{l}\text { CINAHL/EBsco: } 7 \text { articles, } \\
\text { Scopus: } 7 \text { articles, Cochrane: } 0 \\
\text { articles. Puhmed: } 6 \text { articles and }\end{array}$ & \\
\hline$\downarrow$ & $\begin{array}{l}12 \text { articles were obtained based on } \\
\text { the process of identifving }\end{array}$ \\
\hline $\begin{array}{l}\text { CINAHL/EBsco: } 2 \text { articles, } \\
\text { Scopus: } 6 \text { articles, Cochrane: } 1 \\
\text { articles. Puhmed: } 3 \text { articles and }\end{array}$ & \\
\hline$\downarrow$ & $\begin{array}{l}7 \text { articles were obtained based on } \\
\text { the process of identifving }\end{array}$ \\
\hline $\begin{array}{l}\text { CINAHL/EBsco: } 2 \text { articles, } \\
\text { Scoups: } 3 \text { articles, Cochrane: } 0 \\
\text { articles Puhmed } 7 \text {. articles and }\end{array}$ & \\
\hline
\end{tabular}

\section{RESULTS AND DISCUSSION}

Based on the search results, 7 articles met the criteria. After the analysis and identified the readiness of teenage girls in dealing with menarche, these were consists of two categories, including internal and external readiness. The internal readiness was age $(n=5)$ and knowledge $(n=4)$, while the external readiness was family $(n=7)$ and school $(n=6)$. 
Anita Setyawati : A Literature Review: Urban Teenagers' Readiness to Improve The Quality of Life

\section{Age}

Age was the most influences the readiness of teenage girls to face menarche. The results of many studies explained that the age of teenage girls when menarche was in the range of 11-14 years (Gultie, Hailu, \& Workineh, 2014; Marvan \& Alcala-Herrera, 2014; Miiro et al., 2018; Rabiepoor, Valizadeh, \& Barjasteh, 2017; Sørensen et al., 2013). Other studies have shown that menarche age was between 11-17 years but the most was at the age of 15 years (Choudary \& Talwar, 2016). Age affects the level of maturity and mindset, the higher of the age level, the higher level of readiness among teenage girls to face anything including menstruation.

The relationship between age and readiness to face menarche was the younger of age among students, the low level of readiness to receive menstrual events, so that menarche was a surprising disorder (Suryani \& Widyasih, 2008). The early age also affects the behavior post menarche. Some studies were suggested that age did not directly affect to menarche readiness, but it has a major influence in the period post menarche or menstruation. The results showed that teenage girls who have experienced in early menarche were more likely to engage in sexual and romantic activities with older men and also received more positive attention and feedback from older men (Batres \& Perret, 2016). At the age of 11 years, the teenage girls were experiencing a transition between elementary and secondary schools, so it has been the influence and development of hormones and makes attraction to men. As well as higher school attendance so the networking of friends was expanding with an interest in older men in high school.

Women who have experienced menarche have higher estradiol levels as teenagers until early adulthood. This reproductive hormone has been found to influence the feminine appearance (Batres \& Perret, 2016). For example, women with higher estrogen levels were more likely to have a feminine body shape and were judged to be more attractive so that a sense of attraction between men and women was higher. Then more complete education was needed, not only about the readiness of menarche but also about changes condition that will occur after menarche. And it was necessary to increase mental readiness according to the age of teenager and the need for a companion especially to be better prepared and have positive thinking about menstruation or menarche.

\section{Knowledge}

Menarche readiness among teenage girls was influenced by knowledge about menarche and menstruation. Based on the study results from previous studies revealed that girls who ha prior knowledge were better prepared to face menarche (Crawford, Menger, \& Kaufman, 2014; Gultie et al., 2014; Rabiepoor et al., 2017; White, 2013). However, because there was still a taboo feeling, teenage girls find it difficult to find 
Anita Setyawati : A Literature Review: Urban Teenagers' Readiness to Improve The Quality of Life

the information so they were lack of knowledge of menarche. The results of the study stated that teenage girls had never consulted a doctor but were more informed by the mother as the first informant in asking and telling about what had happened to her body including menstruation and menarche (Crawford et al., 2014; Gultie et al., 2014; Miiro et al., 2018; Rabiepoor et al., 2017).

The knowledge that needs to be known about menarche was the use of tools for personal hygiene, such as sanitary napkins, the time replacing pads in 24 hours, washing materials, using disposable protectors, reasons for choosing protection (Miiro et al., 2018). In addition, the knowledge that needs to be known is about the meaning of menstruation, the length of menstruation, the amount of blood that comes out, the level of pain, the first feeling during menstruation, and problems during menstruation (Rabiepoor et al., 2017)

The knowledge was directly proportional to the emotion among teenage girl in menarche period. Some study results reported that teenage have negative views during the first menstruation period (Crawford et al., 2014; Marvan \& Alcala-Herrera, 2014; Rabiepoor et al., 2017; White, 2013). The results of other studies also mentioned that 99 out of 100 respondents said that they were worried about menstruation. As many as $71 \%$ of girls lack of knowledge and they were not psychologically prepared about menstruation and $72 \%$ was lack of information about how to use pads before menarche (Kapoor \& Khari, 2016).

Teenage girls define menarche as something frightening, confusing and dirty. The research results in South Korea explain that the majority of students reported were not feeling happy to menarche in various reasons, including pain, discomfort, shame, and discomfort associated with changes that will occur (Kwon \& Park, 2018). However, other studies revealed that pre-menarche among teenage girls report that they feel mature, more mature, natural, healthy, and surprised when they have experienced their first menstruation (Rados, Bikic, \& Peric, 2017). This difference results can occur because the majority of girls have curiosity, level of knowledge, educational information needs and a sense of openness to what was happening to their bodies including menarche. This was also influenced by parenting factors and stress coping among teenage girls when menarche.

Knowledge or education was not only given to teenage girls but it was better for boys as well. The results showed that the perceptions of young women after menarche or during their menstruation had to limit the distance to men (Miiro et al., 2018). This was supported by the results of other studies that explain young women have a perception that menstruation shows that women can have babies and become adults (Kwon $\&$ Park, 2018). In addition, teenage girls were sometimes embarrassed when menstruation contaminates their clothes and others will see it. It was also necessary to educate peers, especially men, that 
Anita Setyawati : A Literature Review: Urban Teenagers' Readiness to Improve The Quality of Life

menstruation was natural and normal condition among girls. The research results in Croatia mention the information about menstruation was less detailed in educational institutions (Rados et al., 2017).

Therefore, it was necessary to attempt increasing the knowledge among teenage girls to prepare them to face menarche and the need for a discussion group consisting of peers and mentors both teachers, parents (mothers), siblings, or friends at a higher level to share about menstrual experiences or menarche.

\section{Family}

Based on the results of the current study it was known that the mother was the source of information about menstruation. It was known that $88 \%$ of teenage girls told to their mothers at the same day they experience menarche (Marvan \& Alcala-Herrera, 2014) and get information about care or hygiene during menstruation from the mother (Gultie et al., 2014; Miiro et al., 2018). On the other hand, teenage girls never discuss menarche or menstruation with their fathers (Miiro et al., 2018). The results of other studies mention family support can be obtained also from siblings, especially sisters (Gultie et al., 2014). Nevertheless, the mother was still considered as the main source of information for teenage girls when facing menarche. This result was congruent with other studies that $62.89 \%$ of pre-menarche girls stated that mothers were the main source for getting information about menstruation (Dessie \& Tesfaye, 2017).

The role of the mother becomes very important in the preparation of menarche in pre-menarche among teenage girls so that the mother's educational background will influence the information conveyed to young women. Mothers who have good formal education did not consider the topic of menstruation to be taboo and can provide sufficient knowledge about menstruation for their children (Gultie et al., 2014). Therefore, to prevent a pre-menarche young woman from having wrong knowledge about menstruation, a mother should be able to increase the knowledge possessed from various sources that were true and trustworthy, able to process the information obtained, and able to re-convey the right information to teenage girls in pre-menarche period.

\section{School}

The education institution such as schools become external factors that affect the readiness of teenage girls when menarche. The factor of the school was consist of teachers and friends, and school facilities. The study results reported that teenage girls had discussed menstruation in class with teachers and fellow friends (Gultie et al., 2014; Miiro et al., 2018; Rabiepoor et al., 2017). In addition, the other study results revealed that female teachers and friends, whether peers or close friends were a source of information about menstruation for teenagers in pre-menarche (Dessie \& Tesfaye, 2017; Marvan \& Alcala-Herrera, 
Anita Setyawati : A Literature Review: Urban Teenagers' Readiness to Improve The Quality of Life

2014; Miiro et al., 2018; Rabiepoor et al., 2017). However, other studies reported that information about menstruation was less detailed in educational institutions (Rados et al., 2017). This shows that the role of the teacher in conveying information about menstruation was mostly done informally or personally so that the information submitted was still diverse and not standardized.

Therefore, there should be a standard learning plan or subject about menstruation so that the teacher did not only use an informal or personal approach but can also provide formal teaching in the classroom. This teaching process should be delivered early on at the primary education level or in pre-menarche time.

\section{CONCLUSION}

The readiness of teenage girls to face menarche consists of internal and external readiness. The internal readiness consists of age and knowledge. The external readiness consists of social support. The external readiness among urban teenagers was already good but lack of internal readiness. Therefore, counseling and health education was needed relating to menarche starting from elementary school children.

\section{REFERENCES}

Batres, C., \& Perret, D. I. (2016). Early menarche is associated with preference for masculine male faces and younger preferred age to have a first child. Evolutionary Psychology, 14(2).

Choudary, R., \& Talwar, I. (2016). Age At Menarche And Menstrual Characteristics Of Adolescent Girls Of Ambala, Haryana. Ind. J. Phys. Anthrop. \& Hum. Genet, 35(1), 83-101.

Crawford, M., Menger, L. M., \& Kaufman, M. R. (2014). This is A Natural Process: Managing Menstrual Stigma in Nepal. Culture, Healt \& Sexuality: An International Jpurnal for Research, Intervention and Care, 16(4), 426-439. https://doi.org/10.1080/13691058.2014.887147

Dessie, Y., \& Tesfaye, K. (2017). Attitude, Preparation, and Physical Self-Concept as Factors Influencing Emotional Expectation of Menarche among Premenarcheal School Girls in Yewketfana Primary School. Global Journal of HUMAN-SOCIAL SCIENCE: A Arts \& Humanities - Psychology, 17(1).

Gultie, T., Hailu, D., \& Workineh, Y. (2014). Age of Menarche and Knowledge about Menstrual Hygiene Management among Adolescent School Girls in Amhara Province, Ethiopia: Implication to Health Care Workers \& School Teachers. Plos One, 9(9), 1-9. https://doi.org/10.1371/journal.pone.0108644

Kapoor, A., \& Khari, S. (2016). Knowledge, Attitude and Socio-cultural Beliefs of Adolescent Girls towards Menstruation. Journal of Nepal Paediatric Society, 36(1), 42-49.

Kwon, J. S., \& Park, S. (2018). Adaptation to Transition: Meaning of Menarche for Female Adolescents in South Korea. The Journal of Early Adolescence. 
Anita Setyawati : A Literature Review: Urban Teenagers' Readiness to Improve The Quality of Life

Marvan, M. L., \& Alcala-Herrera, V. (2014). Original Study Age at Menarche, Reactions to Menarche and Attitudes towards Menstruation among Mexican Adolescent Girls. North American Society for Pediatric and Adolescent Gynecology, 27, 61-66. https://doi.org/10.1016/j.jpag.2013.06.021

Miiro, G., Rutakumwa, R., Nakiyingi-miiro, J., Nakuya, K., Musoke, S., Namakula, J., ... Weiss, H. A. (2018). Menstrual health and school absenteeism among adolescent girls in Uganda ( MENISCUS ): a feasibility study. BMC Women's Health, 18(4), 1-13. https://doi.org/10.1186/s12905-017-0502-z

Proverawati, A., \& Misaroh, S. (2009). Menarche Menstruasi Pertama Penuh Makna. Yogyakarta: Nuha Medika.

Rabiepoor, S., Valizadeh, R., \& Barjasteh, S. (2017). Study of Menstrual Attitudes and Knowledge among Postmenarcheal Students, in Urmia, North West of Iran. International Journal of Pediatrics, 5(41), 4991-5001. https://doi.org/10.22038/ijp.2017.21905.1831

Rados, S. N., Bikic, Z. M., \& Peric, I. R. (2017). Psychometric properties of the Expected/Experienced Emotions related to Menarche Scale. In Book of Selected Proceedings. University of Zadar, Department of Psychology.

Sørensen, K., Juul, A., Christensen, K., Skytthe, A., Scheike, T., \& Jensen, T. K. (2013). Birth size and age at menarche: a twin perspective. Human Reproduction, 28(10), 2865-2871. https://doi.org/10.1093/humrep/det283

Sukarni, I., \& Wahyu, P. (2013). Buku Ajar Keperawatan Maternitas. Yogyakarta: Nuha Medika.

Suryani, E., \& Widyasih, H. (2008). Psikologi ibu dan anak. Yogyakarta: Fitramaya.

White, L. R. (2013). The Function of Ethnicity , Income Level, and Menstrual Taboos in Postmenarcheal Adolescents ' Understanding of Menarche and Menstruation. Sex Roles, 68, 65-76. https://doi.org/10.1007/s11199-012-0166-y 